\title{
PERFORMANCE ENHANCEMENT OF A DOUBLE PASS SOLAR AIR HEATER USING V-CORRUGATED ABSORBER PLATE AND STEEL WOOL
}

\author{
MOHAMMED A. MOHAMMED SALEH \& OMAR MOHAMMAD HAMDOON
}

Mechanical Department, Collage of Engineering, University of Mosul, Iraq

This study included an experimental investigation for the purpose of improving the performance of a conventional double-pass solar air heater at the climatic conditions of Mosul city/Iraq by replacing the flat absorber plate of the conventional solar air heater with a V-corrugated plate and adding steel wool in the lower passage of the air heater while keeping all dimensions constant for the two heaters. The two heaters were operated together under the same conditions and at a constant air flow $0.0416 \mathrm{~kg} / \mathrm{s}$. The results showed that the thermal efficiency and air temperature exiting from the solar heater can be improved using the improvements that have been indicated. As the average thermal efficiency was $66.78 \%$ for the improved heater and $30.35 \%$ for the conventional heater in the month of March 2020. The results also showed that the improved heater retains the heat gained from solar intensity for a longer period compared to the conventional heater at a constant solar radiation intensity. These improvements also contributed to a clear increase in the temperature of the air exiting the system. The maximum difference in the temperature of the air entering and leaving the heaters in February 2020 reached $28.75^{\circ} \mathrm{C}$, and $16.75^{\circ} \mathrm{C}$ for the improved and conventional heaters, respectively. The results also proved that the improvements over the conventional system led to a reduction in the amount of heat lost from the solar heater.
\end{abstract}

KEYWORD: Solar air Heater, V-Corrugated Absorber Plate, Steel Wool.

Received: Feb 23, 2021; Accepted: Mar 13, 2021; Published: Mar 25, 2021; Paper Id.: IJMPERDAPR202132

\section{INTRODUCTION}

Solar air heater converts solar energy into useful heat energy. Generally, a solar air heater acts as a heat exchanger that transfers heat to the air passing through the system. The thermal performance of the solar air heater is affected by various factors, such as the amount of solar radiation falling on it, the size and design of the absorption area, the design and orientation of the heater, the temperature of the air entering the heater, and the rate of air mass flow through it. The solar air heater is generally used to produce energy at low to moderate temperatures. Despite its low efficiency, it has many advantages such as its cheap price, ease of maintenance, and its ability to improve indoor air quality[1]. In general, solar air heaters can be divided into the following two main types [2]:

- Single pass solar air heaters: They are the simplest types of solar air heaters and they mainly consist of an air flow channel, a glass cover, an absorber plate and the structure of the heater coated with insulating material. The absorber plate is placed at the bottom of the airflow channel and the top of the channel is covered with one or more transparent glass caps. The solar radiation passes through the glass cover and is absorbed by the absorber plate as the heat transfers from the hot absorber plate to the air flowing through the channel.

- Double-pass solar air heaters: in this type of solar air heaters, there are two channels for air flow, as the air 
passes through the upper channel and then changes direction at the end of the passage to enter the lower channel, and the absorber plate separates the two passages.

Despite the many advantages of the two types of solar air heater, its main disadvantage is its low efficiency, so many studies have focused on the best ways to improve its performance.

An experimental and theoretical study was conducted at the climatic conditions of Baghdad to test the thermal performance of single pass solar air heaters with five different designs by Rashid, T.A. and Saleh, A.A.M. [3]. The five designs of solar heaters included: a conventional flat plate solar heater, a finned absorber plate solar air heater, a corrugated absorber plate solar heater, a flat plate solar heater and an iron wire mesh, and a flat plate solar heater with a porous medium placed on it. The tests were conducted at three air mass flow rates between $(0.016-0.027 \mathrm{~kg} / \mathrm{s})$. The results showed that the solar air heater with a porous medium has the highest value of efficiency $56 \%$, followed by the heater with a wire grid with an efficiency $51 \%$. While the efficiency of the wave plate solar heater was $34 \%$, and the efficiency of the finned heater $30 \%$. The lowest efficiency was for the conventional heater, with an efficiency of $26 \%$. Wang, D.et al. [4] conducted an experimental study aimed at increasing the efficiency of a single-pass solar air heater by creating S-shaped ribs on the absorber plate, with gaps to reduce airflow resistance. The researchers showed that this design enhances the thermal efficiency of the solar air heater, as it provides a better heat transfer between the absorber plate and the air. The results showed the possibility of improving the thermal efficiency by $(13 \%-48 \%)$ under different operating conditions as a result of adding ribs. Bashria, A. et al. [5] conducted a theoretical study to test the effect of a number of factors such as air mass flow rate, flow channel depth and heater length on the thermal performance and pressure drop of two single-pass and double-pass solar air heaters, with and without the use of porous media. The results of the researchers showed that the thermal efficiency of the double-pass heater is higher than the thermal efficiency of the single-pass heater by $(10 \%-20 \%)$, and the percentage of increase in the thermal efficiency when using the porous material is $8 \%$. Kumar, C. and Singh, H. [6] made a comparison of a conventional single-pass solar heater with a double-pass solar heater reinforced with a porous material (gravel, foil) in the lower passage of the system. The results showed that the efficiency of the improved system by adding the porous material reached $67 \%$, while the efficiency of the conventional system was $49 \%$ at the same operating conditions. The researchers attributed this improvement in efficiency to the variation in the amount of heat lost from the heater, especially around the absorber plate, as the amount of heat lost in the double-pass heater is significantly less due to the presence of pebbles that help to retain heat and thus increase the efficiency of the system.

Dhatkar, S.A. et al. [7] studied, in his experimental study, three different types of solar air heaters (single-pass heater, double-pass heater, and double-pass heater enhanced with the addition of porous material). The researchers studied many factors to analyze the performance of solar air heater, such as the amount of heat movable, pressure drop and flow type. The researchers observed that the double pass solar air heater with porous media gives the highest thermal efficiency compared to the heater without porous media. For example, at a constant flow rate of air mass of $0.01625 \mathrm{~kg} / \mathrm{s}$, and solar intensity $1423 \mathrm{~W} / \mathrm{m}^{2}$, the thermal efficiency of the solar air heater without porous media was $79.9 \%$ while for the solar air heater with porous media the thermal efficiency was $92 \%$. The researchers also found that the double-pass solar air heater shows a significant increase in performance compared to the conventional system.

An experimental study was carried out by Gupta, B.et al. [8] to study the effect of porous media (glass wool and steel wool) on a double-pass solar air heater and compare it with a conventional single-pass air heater. The researchers showed that the porous media provides a large area for heat transfer and has a high heat transfer coefficient, which 
increases the thermal efficiency. The results of the experiments also showed that the thermal efficiency of the solar energy heater depends on the flow rate of the air mass, as the thermal efficiency increases when the flow rate of the air mass increases. Finally, the researchers' results showed that the thermal efficiency of the double-pass solar air heater increases about $40.23 \%$ with steel wool and $33.1 \%$ with glass wool compared with the conventional single-pass solar air heater. In her experimental study, Afaq J. Mahmood [9] discussed the effect of the use of baffles and combined wire layers of baffles on the efficiency and performance of the solar air heater. The results showed that the highest thermal efficiency was for the double-pass solar air heater with seven baffles $68.1 \%$ at an air flow $0.032 \mathrm{~kg} / \mathrm{s}$ and a depth $3 \mathrm{~cm}$ for the lower passage, while the highest temperature difference was $54^{\circ} \mathrm{C}$ at an air flow $0.011 \mathrm{~kg} / \mathrm{s}$, seven layers of baffles and a height $3 \mathrm{~cm}$ of the lower passage. The theoretical study presented by Fudholi, A.et al. [10] includes the effect of air mass flow rate, number and height of fins installed on the absorber plate on the thermal efficiency of three different types of air heaters. The first type is a double-pass solar air heater with upper and longitudinal fins, the second type is a double-pass air heater with lower longitudinal fins, and the third type is a double-pass solar air heater with upper and lower longitudinal fins. The researchers found that heater efficiency increases with the number and height of fins. For mass flow rate $0.02-0.1 \mathrm{~kg} / \mathrm{s}$, the efficiency of solar air heaters increases by about 36-73\% when using upper fins, (35-37\%) when using lower fins, and (46-74\%) when using upper and lower fins.

In this experimental study, we aim to study the improvement in the performance of a double-pass solar air heater as a result of the use of a graduated absorber plate, as well as the addition of steel wool for the bottom pass under various conditions such as the intensity of the solar radiation falling on the heater and the ambient temperature during the winter months in the city of Mosul, Iraq.

\section{THEORETICAL ANALYSIS}

The thermal efficiency $(\eta)$ is defined as the ratio of useful energy to the total solar radiation incident at a given time, expressed by the formula [11]:

$$
\eta=\frac{Q_{\mu}}{I \cdot A_{C}}
$$

The difference between the amount of heat received (incident radiation) and the lost heat of the solar heater represents the useful heat gain from the solar heater $\left(Q_{u}\right)$ while $A_{C}$ represents the area of the section through which the solar radiation is received $\left(\mathrm{I} \mathrm{W} / \mathrm{m}^{2}\right)$.

$\left(Q_{i}\right)$ represents the heat received by the solar air heater by the following equation:

$$
Q_{\mathrm{i}}=\mathbf{I} \cdot \mathrm{A}_{\mathrm{c}}
$$

I. $A_{c}(\tau \alpha)$ represents the amount of heat received from the solar collector entering the upper channel.

When the solar heater receives solar energy, the temperature of the absorber plate rises and is higher than the ambient temperature, so part of the energy will be lost to the environment. The heat loss $\left(\mathrm{Q}_{\mathrm{o}}\right)$ of the heater depends on the air temperature entering the solar heater and the overall heat transfer coefficient $\left(\mathrm{U}_{\mathrm{L}}\right)$.

The value of $Q_{0}$ can be represented by the following equation:

$$
Q_{o}=U_{L} A_{c}\left(T_{p}-T_{a}\right)
$$


From the steady-state thermal equilibrium equation, the useful heat gain $\left(\mathrm{Q}_{\mathrm{u}}\right)$ represents the difference between the amount of heat received and the heat lost from the solar collector:

$Q_{u}=Q_{i}-Q_{o}$

In general, according to the (Hottel-Bliss) equation:

$Q_{u}=I \cdot A_{c}(\tau \alpha)-U_{L} A_{c}\left(T_{p}-T_{a}\right)$

From the above, the instantaneous thermal efficiency ( $\eta$ ) (at a specific time) is as follows:

$\eta=(\tau \alpha)-U_{L} \frac{\left(T_{p}-T_{a}\right)}{I}$

Since the useful heat gain from solar radiation equals the heat that will gain the air passing through the heater, the efficiency can also be expressed by the following equation:

$\eta=\frac{\dot{m}_{\text {air }} c p_{\text {air }} \Delta T}{\text { l.A }}$

While the overall heat transfer coefficient can be represented by the equation:

$\mathrm{U}_{\mathrm{L}}=\frac{\mathrm{Q}_{0}}{\mathrm{IA}_{\mathrm{c}}\left(\mathrm{T}_{\mathrm{p}}-\mathrm{T}_{\mathrm{a}}\right)}$

\section{THE MANUFACTURE OF THE TWO HEATERS}

In this paper, two double-pass solar air heaters were designed and manufactured. The first heater is a conventional solar heater, and the second is an improved solar heater by using a $60{ }^{\circ}$ "V" corrugated absorber plate instead of the flat plate used in the conventional heater. Steel wool was also added in the lower channel. For the purpose of manufacturing the two systems, materials available in the local market were used. Plank wood with a thickness of $1.8 \mathrm{~cm}$ was used in building the structure of the two systems, and glass with a thickness of $6 \mathrm{~mm}$ was used as the top cover for the two systems. To reduce losses from the sides and bottom of the two systems, a foam insulation with a thickness of $2 \mathrm{~cm}$ was added. Aluminum alloy (1060-H16) with thickness of $0.8 \mathrm{~mm}$ was chosen as the absorber plate. The absorber plate for both heaters was coated with higher thermal conductive black paint (ETIKA). The area of the flat absorber plate was $2 \mathrm{~m}^{2}$ while the area of the graduated plate was $3.88 \mathrm{~m}^{2}$. Steel wool was added in sufficient quantity to fill the lower channel (length of $2 \mathrm{~m}$, height of $7.5 \mathrm{~cm}$ and width of $10 \mathrm{~cm}$ per channel), Figure (1).

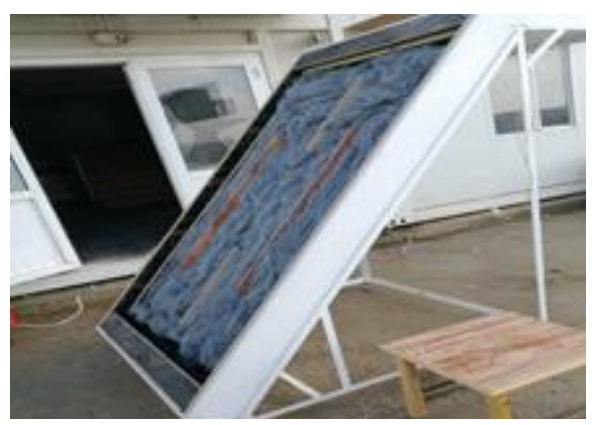

Figure 1: Steel Wool in the Lower Channel 
For the purpose of drawing air into the system, three DC fans were installed with a capacity of $0.3 \mathrm{~A}$ for one fan, where the power of one fan was $3.6 \mathrm{~W}$ for each heater. The fan speed is controlled by connecting it with a control device through which it can change the propellant force of the fans and thus control the speed and amount of air entering the system.

Work in the two devices included the use of the following measuring devices:

Type K thermocouple, diameter $0.4 \mathrm{~mm}$. The thermocouple was installed after welding its outer end by a special welding machine on the glass cover of the heater with three points (the upper, lower and middle end), as well as three points on the absorber plate as well as for the upper and lower channel. Where 14 thermocouples were used by adding two thermocouples to measure the air temperature entering and leaving the solar heater is fixed using adhesives. Figure (2) shows the mounting points for thermocouples of the conventional heater.

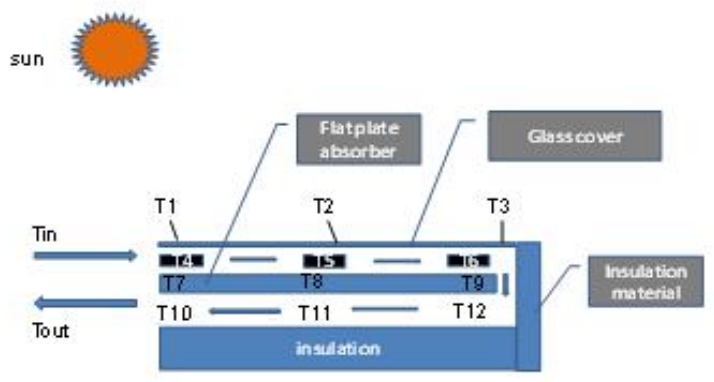

Figure 2: Mounting Points for Thermocouples.

- $\quad$ Solar meter type SM 206.

- $\quad$ Anemometer type GM 816.

- Voltmeters and a thermometer to measure the temperature, for the purpose of making a comparison with the thermocouple reading and determining the error rate.

- Twenty-eight pieces (Max 6675) electronic components, which act as voltage amplifiers. Fourteen parts were used for each system in order to convert the low voltage generated in the thermocouple into a voltage that the Arduino piece could read.

Electronic processor piece (Arduino) type (MEGA 2560), which enables us to convert the temperature readings to the excel program. A piece was used for each device (system), Figure (3). The thermocouples were connected with the electronic parts (Max 6675) and then they were connected with the Arduino piece (2560 Mega) and connected to the computer. By using a 12 volt DC battery, the two systems are operated by the on / off button connected to the operating circuit. Figure (4) shows the final design of the two systems in operation. The two solar air heaters were directed to the south side using a directional compass, after placing them on the base (the bearing) designed at an angle of inclination $55^{\circ}$ for the months (December, January, February and March) to make the most of the amount of solar radiation falling on the solar heater. And by using a suitable program (code) that was written using the Arduino technique, for the purpose of recording the readings of thermocouples directly inside the computer. Also, QLX DAQ was used to link the readings, which enables us to store readings directly inside the Excel program. All the thermocouple readings were recorded in this way, while the solar radiation intensity readings were recorded manually. The reading recording program was set up so that the thermocouple readings were recorded every 10 minutes and stored in the computer for each heater separately. 


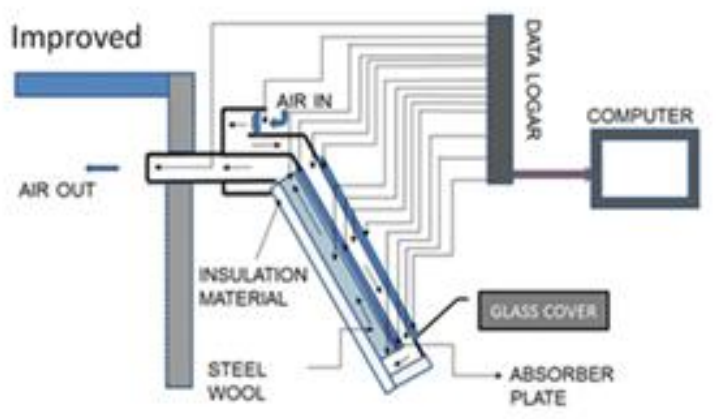

Figure 3: The Final Design Diagram of the Improved Solar air Heater.

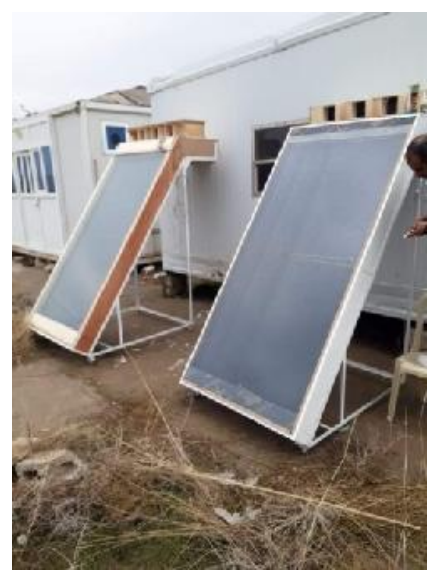

Figure 4: Conventional and Improved Solar air Heater.

\section{EXPERIMENTAL UNCERTAINTY}

For the purpose of determining the error rate associated with the experimental measurements before the experiment, it is necessary to determine the variables that directly affect the value of the thermal efficiency calculated from the following relationship:

$$
\eta=\left[\frac{\mathrm{miC}_{\mathrm{p}}\left(\mathrm{T}_{\text {out }}-\mathrm{T}_{\mathrm{in}}\right)}{\mathrm{I} \cdot \mathrm{A}_{\mathrm{c}}}\right]
$$

Where $\dot{m}$ represents the air mass flow rate into the air heater and $C_{p}$ the heat capacity of the air, $T_{\text {out }}, T_{\text {in }}$ represents the temperature of the air entering and leaving the solar heater respectively. Also, $\mathrm{I}$ is the solar radiation intensity and $\mathrm{A}_{\mathrm{c}}$ represents the cross-sectional area of the airflow. Since the air mass flow rate is a function of the density and volume of the flowing air, and of a constant cross-sectional area, $A_{c}$. Assuming the properties of the air are constant over the change in the measured air temperature in the experiment, the mass flow rate is a function of velocity. The device used to measure air velocity of the type (GM 816) has an error rate of 5\% and the device used in measuring the solar intensity (SOLAR METER) type (SM 206) has an error rate of 5\%, in addition to the rate of error in reading The thermocouple used in the experiment (TYPE $\mathrm{K})$ is $\left(2.2^{\circ} \mathrm{C} \pm 0.75 \%\right.$ per $\left.\mathrm{C}\right)$.

Using the following equation:

$$
\frac{\omega_{\eta}}{\eta}=\left[\left(\frac{\omega_{\mathrm{m}}}{\mathrm{m}}\right)^{2}+\left(\frac{\omega_{\Delta \mathrm{T}}}{\Delta \mathrm{T}}\right)^{2}+\left(\frac{\omega_{\mathrm{I}}}{\mathrm{I}}\right)^{2}\right]^{\frac{1}{2}}
$$


Where $\left(\frac{\omega_{\mathrm{m}}}{\mathrm{m}}\right)$ represents the percentage of partial error of the amount of air flowing, and $\left(\frac{\omega_{\Delta T} \mathrm{~T}}{\Delta \mathrm{T}}\right)$ represents the partial error percentage of the air temperature difference, while $\left(\frac{\omega_{I}}{\mathrm{I}}\right)$ represents the percentage of partial error in measuring the intensity of solar radiation. Table (1) shows the Uncertainties of measured and resulted data for the conventional and improved heaters.

Table 1: The Uncertainties of Measured and Resulted Data for Both Heaters

\begin{tabular}{|l|c|c|c|c|c|c|}
\hline Type & $\cdots \cdots \mathbf{C}$ & $\mathbf{m}(\mathbf{k g} / \mathbf{s})$ & $\mathbf{I}\left(\mathbf{w} / \mathbf{m}^{2}\right)$ & $\eta \%$ & $\ldots \%$ & $\ldots \%$ \\
\hline Conventional & 20.75 & 0.02 & 1098.32 & 18.78 & 0.1 & 1.33 \\
\hline & 32.25 & 0.02 & 667 & 29.19 & 0.1 & 2.07 \\
\hline Conventional & 19.25 & 0.0416 & 892.4 & 34.36 & 0.21 & 1.02 \\
\hline Improved & 31.75 & 0.0416 & 667.25 & 74.46 & 0.21 & 0.99 \\
\hline
\end{tabular}

The resulting error of the efficiency for the improved solar air heater efficiency is approximately $2.07 \%$.

\section{RESULTS AND DISCUSSION}

Experiments were conducted on the solar air heating systems (conventional and improved) and their performance was tested in the weather conditions of the city of Mosul, Iraq $\left(36.348^{\circ} \mathrm{N}, 43.1577^{\circ} \mathrm{E}\right)$ during the months (December, January, February and March), for a daily reading period from 8:00 am to 4:00 pm. The following table shows the number of days the readings were recorded for each month.

Table 2: The Number of Days of Recording the Readings

\begin{tabular}{|l|c|c|}
\hline Month & Days & Total \\
\hline December & $7,13,26,28$ & 4 \\
\hline January & $1,2,3,7,11,12,14,17,25,27,28$ & 11 \\
\hline February & $2,5,7,8,10,11,12,15,21$ & 9 \\
\hline March & $6,10,12,13,15,16,23,24$ & 8 \\
\hline
\end{tabular}

All experiments were conducted at a constant air mass flow of $0.0416 \mathrm{~kg} / \mathrm{s}$. The following paragraphs present the most important results of the experiments.

\section{Variation of Hourly Solar Radiation (I) on the Heater For the Hour Months}

In general, the intensity of solar radiation is the main factor affecting the efficiency and specifications of the solar air heater, in addition to its effect on the ambient temperature. Figures $(5,6,7$, and 8) show the daily change in solar intensity for the selected days during the four months. Figure (5), shows the change in the intensity of solar intensity for days 13,26 , and 28 of December, where we note that the maximum values of the radiation intensity are confined between 12:00 and 12:50 in clear atmospheres without clouds, as the sun is almost perpendicular to the surface of the air heater The maximum value of the intensity of solar intensity $923.78 \mathrm{~W} / \mathrm{m}^{2}$ on December 13 at 12:30 hours, while the maximum value of radiation intensity for days 26 and 28 December was $788.8 \mathrm{~W} / \mathrm{m}^{2}$ And $910.7 \mathrm{~W} / \mathrm{m}^{2}$ at 12:50 and 12:40, respectively. This change in the intensity of solar radiation and its maximum and minimum values varies from day to day, as well as during daylight hours, depending on the effects of clouds and dust. From Figure (6), which represents the amount of change in solar radiation intensity for days 2, 14 and 27 January, we find that the highest value of sun radiation $1117.04 \mathrm{~W} / \mathrm{m}^{2}$ for January 27 was at 12:40. While the highest values of radiation intensity were recorded for the days 2 and 14 January 1077.7 W/m $\mathrm{m}^{2}$ and $1069.0 \mathrm{~W} / \mathrm{m}^{2}$, respectively, at 12:40 hours as well. This shows us that it is difficult to predict the amount 
of solar intensity due to its change according to the change of weather conditions and the angle of incidence of radiation on the outer surface (glass cover) of the solar air heater. Figure (7) shows the change in the intensity of solar intensity during the daylight hours for days 11,15 and 21 February, as we note that the highest rate of solar radiation among these three days was on February $11\left(842.12 \mathrm{~W} / \mathrm{m}^{2}\right)$, while the maximum radiation value for two days 15 and 21 of January was $833.05 \mathrm{~W} / \mathrm{m}^{2}, 697 \mathrm{~W} / \mathrm{m}^{2}$, respectively. The intensity of solar radiation for days 6, 12 and 23 of March as shown in Figure (8) indicates the fluctuation of solar intensity on the day of March 6, due to the appearance of some intermittent clouds that led to a decrease in the intensity of solar radiation falling on the air heater, thus reducing the average daily solar radiation intensity. The highest solar intensity $1187.48 \mathrm{~W} / \mathrm{m}^{2}$ was recorded on March 23 at 13:00, while the maximum value of radiation for days 6 and 3 March was $1063.54 \mathrm{~W} / \mathrm{m}^{2}$ at $12: 40$ and $1006.9 \mathrm{~W} / \mathrm{m}^{2}$ at 12:00 respectively.

\section{Variation of the Ambient Temperature $\left(T_{a}\right)$ for the Four Months}

The ambient temperature is affected by the intensity of solar radiation, and this effect varies during daylight hours and varies from day to day according to the difference in radiation intensity. We notice from the figures drawn for different sunny days of each month that the temperature of the surroundings begins to gradually rise from after sunrise until it reaches its maximum value at midday and then begins to slowly decrease after 12:00 and then begins to decrease clearly after 14:00 to reach its lowest value during the reading recording period at 16:00, that is, when the last reading of the solar intensity figures $(9,10,11,12)$. The change in the intensity of solar radiation directly affects the temperature of the air entering the solar heater. We notice from Figure (10), which shows the change in the temperature of the surroundings for the days of 27 and 25 January, that the temperature of the surroundings begins to increase with the increase in the intensity of solar radiation during the day and then begins to decrease after 13:00 due to the decrease in the value of solar intensity. But this change is very small, as we notice from the readings on December 27 that the amount of change ranges between $\left(0.25-0.5^{\circ} \mathrm{C}\right)$ and after this time the change is also slight until it reaches its lowest value $16.5^{\circ} \mathrm{C}$ at the end of the reading time at $16: 20$.

\section{Variation of Hourly Temperature Difference $(\Delta T)$ for the Four Months}

Figure (13) shows the difference between the temperature of the air entering and leaving the solar heater for December 26, where we note that the highest difference reached $26^{\circ} \mathrm{C}$ for the improved heater at $12: 40$, while the highest difference for the conventional heater was $23^{\circ} \mathrm{C}$ at $12: 20$ and the difference value is close to when the operation starts at 8:00. Then this difference starts to increase with increasing solar radiation intensity after 9:30 for both the improved and conventional heaters. Also, this difference of the improved heater remains higher than the conventional heater even after midday, because the amount of heat absorbed from the graduated absorber plate is higher than that of the flat plate in addition to the presence of steel wool in the lower passage, which enhances the amount of heat transferred to the air coming out of the heater by convection. Figure (14) shows the difference between the air temperature during daylight hours for the two improved and conventional heaters for January 27. The highest air temperature difference for the improved heater was $28.25^{\circ} \mathrm{C}$ at $12: 50$, while the highest air temperature difference $18.75^{\circ} \mathrm{C}$ for the conventional heater was recorded at 12:40. The nature of the weather represented by the intensity of solar radiation and the presence of clouds and dust affect the value of this difference. In sunny days, this difference is relatively high compared to partial cloudy weather or in the case of dust and strong winds. Certainly, the temperature difference between the improved heater is higher than that of the conventional heater. Figure (15) shows the difference between the air temperature on February 21, where the maximum value of the difference between the air temperature of the improved heater reached $28.75^{\circ} \mathrm{C}$ at $12: 20$ at the intensity of 
solar radiation $960.6 \mathrm{~W} / \mathrm{m}^{2}$. While the maximum difference was recorded for the conventional heater $16.75^{\circ} \mathrm{C}$, at $12: 40$ at the solar radiation intensity $936.16 \mathrm{~W} / \mathrm{m}^{2}$. This difference between the air temperature of the two heaters can be explained by the fact that the flat absorber plate of the conventional heater absorbs less heat from the radiation penetrating to it than that of the improved heater, and thus the response to the change of air temperature associated with the intensity of solar radiation is less than that of the improved heater. In addition, the amount of heat lost from the conventional heater is greater compared to the improved heater. The highest difference in air temperature, $31.75^{\circ} \mathrm{C}$, was recorded for the improved heater for March 12 at 12:30 hours, as shown in Figure (16). While the highest difference in air temperature for the conventional heater was $18.5^{\circ} \mathrm{C}$ at $12: 30$ hours as well. We note from the study of Figure (16) the rise in the difference in air temperature during the month of March for the improved and conventional heaters, due to the increase in the intensity of solar radiation, noting the stability of this difference in the period of peak radiation at 12:30 until 12:50. A slight change may occur during this period, which is due to the stability or slight change in the radiation intensity during this period, and thus the difference stabilizes for a short period, and then this change decreases after 13:00.

\section{Variation of Hourly Thermal Efficiency $(\eta)$ for the Four Months}

The thermal efficiency changes during daylight hours with the change in the intensity of solar radiation, and thus the difference between the temperature of the entering and leaving air from the solar heater of the conventional and improved system changes with the constant air mass flow rate and surface area of the glass cover. The following figures show the difference between the thermal efficiency values for the day of each month during the period of recording the readings, and we note that the best thermal efficiency values were recorded for the improved solar heater during the month of March. Whereas, the thermal efficiency values vary for the other months according to the intensity of the solar radiation falling on the glass cover and thus the difference in the amount of heat absorbed by the absorber plate for both heaters, Fig (17).Figure (18) shows the rate of change of the thermal efficiency of the two conventional and improved heaters over time as of January 27. From the figure it is clear that the thermal efficiency of the solar heater is affected by the amount of solar radiation falling on the glass cover of the heater, the air mass flow rate and the difference between the temperature of the air entering and leaving the heater. Since the intensity of solar radiation varies with time, the thermal efficiency changes with time as well. Since the air flow is constant, the efficiency depends on the intensity of solar radiation and the temperature of the air entering and leaving the air heater for a fixed surface area of the glass cover at $2 \mathrm{~m}^{2}$. The rate of thermal efficiency on this day was $57.49 \%$ for the improved heater, while the rate of thermal efficiency of the conventional heater was $34.96 \%$, meaning that the thermal efficiency of the improved solar air heater exceeds the thermal efficiency of the conventional air heater by $22.53 \%$ for this day due to the improvements made to the conventional heater. Figure (19) shows the change in the thermal efficiency of the improved and conventional heaters over time as of February $21,2020$. The figure shows the clear difference between the efficiency of the improved and conventional solar heater. The greatest efficiency of the improved heater was $78.67 \%$ at $3: 50 \mathrm{pm}$, while the greatest efficiency of the conventional heater was $38.23 \%$ at same hour. And if we take into consideration the calculation of the average daily thermal efficiency for both heaters, we find that the average daily thermal efficiency of the improved heater $50.57 \%$ and the conventional heater $28.26 \%$. So, the average rate of increase in thermal efficiency will be $44.11 \%$ on February 21 . This percentage is not fixed for the solar heater and varies from day to day according to the temperature of the air entering and leaving the heater, as well as according to the intensity of solar radiation for a constant mass flow rate. Figure (20) shows the change in thermal efficiency with the intensity of solar radiation for the two conventional and improved heaters for March 12th. The figure shows the high thermal efficiency of the two heaters in this month, due to the apparent increase the intensity of solar 
radiation, which also led to a clear rise in the temperature of the surrounding air. The average thermal efficiency was $66.78 \%$ for the improved heater and $30.35 \%$ for the conventional heater. We also notice from the figure the change in the shape of the curve in this month, as the thermal efficiency of the improved solar heater continues to increase even after the gradual decrease in the intensity of solar radiation began after 13:20. This is because the amount of heat stored inside the heater is very high due to the solar radiation during the peak period, and the decrease in the outside air temperature is very small compared to a conventional solar air heater for a constant mass flow rate. Also, the high temperature of the air entering the solar heater reduces the amount of energy lost and the overall heat transfer coefficient.

\section{Variation of Hourly Useful Heat Gain $\left(Q_{u}\right)$ for the Four Months}

Figure (21) shows the change of the useful heat gainQ $\mathrm{Q}_{\mathrm{u}}$ for the conventional and improved solar air heater with the intensity of the incident solar radiation on December 26, 2020. As the average useful heat gain on this day reached 23.59 kW.hr and $36.35 \mathrm{~kW} . \mathrm{hr}$ for the conventional and improved heaters, respectively. Thus, the rate of increase in the improvement of the useful heat gain value on this day $35.1 \%$ at a constant flow rate of the amount of air and the length of the reading period of 8 hours. Figure (22) shows the variation of the useful heat gain $\mathrm{Q}_{\mathrm{u}}$ for the conventional and improved solar air heater with the intensity of the incident solar radiation on January 27, 2020. Where we note that the useful heat gain of the improved heater is higher than the useful heat gain of the conventional heater over the length of the reading period of 8 hours. Since the amount of radiation that falls on the two heaters is one and that the rate of constant air flow and the temperature of the air entering the solar heater are the same for the two heaters, it can be concluded that the increase in the useful heat gain for the improved air heater is due to the additives (V-corrugated plate and steel wool) that have enhanced the efficiency and performance of the heaters. The absorber plate increased the surface area absorbing the solar radiation through the glass cover, and the steel wool contributed to raising the air temperature in the lower passage of the solar heater. Where the useful heat gained of the conventional heater was $36.31 \mathrm{~kW} . \mathrm{hr}$, while the useful heat gain of the improved solar heater was $45.57 \mathrm{~kW}$.hr. This leads us to the rate of increase in the useful heat gain by $9.2 \mathrm{~kW}$.hr during the reading period for that day. Figure (23) shows the relationship between the useful heat gain and the intensity of solar radiation falling with the time for February 21,2020 . The highest value of radiation intensity on this day was $960.6 \mathrm{~W} / \mathrm{m}^{2}$ at 12:20, and at this time we notice that the difference in the temperature of the air entering and leaving the improved heater reached $28.5^{\circ} \mathrm{C}$, while the temperature difference between the conventional heater was $15.5^{\circ} \mathrm{C}$. This explains the increase in the useful heat gain for the improved heater. From the figure, we find that the curve path of the useful heat gain of the improved heater is similar to the curve path of the solar intensity at most times, and that the curve path of the heat amount of the conventional heater differs in many points from the path of the radiation, because the amount of heat lost from the conventional heater is higher than that of the improved heater. The useful heat gain for the day was therefore 38.3 kW.hr and $20.62 \mathrm{~kW} . \mathrm{hr}$ for the conventional and improved air warmers, respectively. Figure (24) shows the change in the useful heat gain for the two conventional and improved heaters with the change in the intensity of the incident solar radiation with the time for the day of March 12, 2020. From the study of the figure, we conclude that since the intensity of solar radiation in the month of March is considered high compared to its intensity in the other months of recording the reading, the useful heat gain of the heater is relatively high. The average useful heat gain was $18.99 \mathrm{~kW} . \mathrm{hr}$ and 40.68 $\mathrm{kW} . \mathrm{hr}$ for an average daily reading of 8 hours for the conventional and improved heaters, respectively. That is, the rate of improvement in the useful heat gain was $53.31 \%$, which is a high value compared to the readings on January 27 and February 21. 


\section{Variation of Hourly Overall Heat Transfer Coefficient $\left(\mathrm{U}_{\mathrm{L}}\right)$ for the Four Months}

Figure (25) shows the overall heat transfer coefficient during daylight hours for December 26, 2019, where the overall heat transfer coefficient reached its highest value $0.020163 \mathrm{~kW} / \mathrm{m}^{2} .{ }^{\circ} \mathrm{C}, 0.01252 \mathrm{~kW} / \mathrm{m}^{2} .{ }^{\circ} \mathrm{C}$ for both the conventional and improved heaters consecutively at 12:40 in the afternoon, where we note from these values that the overall heat transfer coefficient of the improved heater is lower than that of the conventional heater due to the retention of the received heat to increase the area of the absorber plate, and the presence of steel wool that stores heat in the lower passage of the solar heater. Figure (26) shows the change of the overall heat transfer coefficient of the two conventional and improved heaters during the daylight hours for January 27, 2020. The daily average value of the overall heat transfer coefficient of the conventional heater was $0.0237 \mathrm{~kW} / \mathrm{m}^{2} .{ }^{\circ} \mathrm{C}$, which is higher than the average daily overall heat transfer coefficient. For the improved heater, which reached $0.0128 \mathrm{~kW} / \mathrm{m}^{2} .{ }^{\circ} \mathrm{C}$ and by calculating the difference between the two parameters, we find that the amount of difference is $0.0109 \mathrm{~kW} / \mathrm{m}^{2} .{ }^{\circ} \mathrm{C}$ for this day's readings, and we note that the temperature of the absorber plate has a direct effect on the value of the overall heat transfer coefficient. The overall heat transfer coefficient value decreases with the increase in the absorber plate temperature. Figure (27) shows the change of the overall heat transfer coefficient of the conventional and improved heaters during the daylight hours of February 21, 2020. From the results, we find that the percentage of the decrease in the overall heat transfer coefficient relative to the improved heater over its value in the conventional heater reached $69.06 \%$, where the daily average value of the overall heat transfer coefficient for the conventional and enhanced heaters is $0.049444 \mathrm{~kW} / \mathrm{m}^{2} .{ }^{\circ} \mathrm{C}, 0.015309 \mathrm{~kW} / \mathrm{m}^{2} .{ }^{\circ} \mathrm{C}$, respectively. From the study of Figure (28), which shows the change in the values of the overall heat transfer coefficient of the conventional and improved heaters for the day of 12 March 2020, we find that there is a decrease in the value of the overall heat transfer coefficient for the two heaters on this day due to the increase in the temperature of the absorber plate and the increase in the ambient temperature for both heaters, where the average daily value of the overall heat transfer coefficient for the two improved and conventional heaters was $0.020163 \mathrm{~kW} / \mathrm{m}^{2} .{ }^{\circ} \mathrm{C}, 0.020198 \mathrm{~kW} / \mathrm{m}^{2} .{ }^{\circ} \mathrm{C}$, respectively.

\section{CONCLUSIONS}

This experimental study included designing two heaters of double-pass solar air heaters similar in dimensions, shape and parts. The first (conventional) heater was modified by adding a v-shaped graduated absorber plate instead of the flat plate and adding steel wool in the lower passage of the second heater (improved). The two heaters were operated together in the same weather conditions of Mosul city / Iraq, for the purpose of comparison between them in terms of performance and efficiency. Among the most important conclusions that were arrived at are:

- The thermal efficiency of the improved solar air heater is higher than that of the conventional heater. The results obtained showed that the daily thermal efficiency was $66.78 \%$ and $30.35 \%$ for the improved and conventional heaters, respectively on March 12, 2020. The rate of improvement is not fixed, it varies from month to month and varies during the same month according to the influencing and variable factors such as: radiation intensity, ambient temperature.

- Increasing the surface area of the absorber plate by using the V-corrugated plate and using steel wool in the lower passage of the improved heater resulted in reducing the heat lost and increasing the useful heat gain. The average daily rate of improvement in the useful heat gain reached $53.31 \%$ on March 12, 2020, as the average useful heat gain on this day reached $40.68 \mathrm{~kW} . \mathrm{hr}$ and $18.99 \mathrm{~kW} . \mathrm{hr}$ for the improved and conventional heaters, respectively. 
- The temperature of the air leaving the improved heater is higher than the air leaving the conventional heater, and since the operating conditions are the same for the two heaters, the average difference between the entering and leaving air temperature reached its highest value on March $12,202031.75^{\circ} \mathrm{C}$ and $18.5^{\circ} \mathrm{C}$ for the enhanced and conventional heaters, respectively.

- The thermal efficiency, air temperature difference and useful heat gain of the improved heater are relatively high compared to the conventional heater. This indicates the success of the improvement that we have introduced to the conventional system. For example in January 27, we find the useful heat gain reached $26.49 \mathrm{~kW} . \mathrm{hr}$ and 45.8 $\mathrm{kW} . \mathrm{hr}$ for the conventional and improved heaters, respectively, so, the amount of heat saved is $19.31 \mathrm{~kW} . \mathrm{hr}$.

\section{NOMENCLATURE}

\begin{tabular}{|c|c|c|c|}
\hline $\mathrm{A}_{c} \mathrm{sct}$ & Solar air heater area, $\left(\mathrm{m}^{2}\right)$ & & Jseful heat gain $(\mathrm{kW})$ \\
\hline $\mathrm{C}_{\underline{\mathrm{D}}}^{\mathrm{c}}$ & Specific heat of air, $(\mathrm{kJ} / \mathrm{kg} . \mathrm{K})$. & $\mathrm{T}$ & Temperature $\left({ }^{\circ} \mathrm{C}\right)$ \\
\hline I & Solar radiation, $\left(\mathrm{W} / \mathrm{m}^{2}\right)$ & & Fverall heat transfer coefficient $\left(\mathrm{W} / \mathrm{m}^{2} .{ }^{\circ} \mathrm{C}\right)$ \\
\hline & Mass flow rate of air, $(\mathrm{kg} / \mathrm{s})$. & & $\begin{array}{l}\text { temperature difference between the air entering and } \\
\text { leaving the solar heater }\left({ }^{\circ} \mathrm{C}\right)\end{array}$ \\
\hline & heat received by the solar air heater $(\mathrm{kW})$ & & \\
\hline
\end{tabular}

\begin{tabular}{|c|l|c|}
\hline \multicolumn{2}{|c|}{ SUBSCRIPTS } & GREEK SYMBOLS \\
\hline im & Improved solar air heater & \\
\hline co & conventional solar air heater & \\
\hline in. & Inlet & \\
\hline out & Outlet & \\
\hline$p$ & Absorber plate & \\
\hline
\end{tabular}

\section{ACKNOWLEDGEMENTS}

The authors wish to thank the University of Mosul for their support in this work.

\section{REFERENCES}

1. Omar Mohammed Hamdoon, 2020. A Review of Solar Air Heaters: Techniques for Thermal Performance Enhancement. AlRafidain Engineering Journal. 25 (2), pp. 46-59.

2. A.E.Kabeel, MofrehH.Hamed, Z.M.Omara, A.W.Kandeal, 2017. Solar air heaters: Design configurations, improvement methods and applications - A detailed review. Renewable and Sustainable Energy Reviews. 70, pp. 1189-1206.

3. Rashid, T.A. and Saleh, A.A.M., 2016. Experimental and theoretical study for performance enhancement of air solar collectors by using different absorbers. Al-Khwarizmi Engineering Journal, 12(3), pp.110-120.

4. Wang, D., Liu, J., Liu, Y., Wang, Y., Li, B. and Liu, J., 2020. Evaluation of the performance of an improved solar air heater with "S" shaped ribs with gap. Solar Energy, 195, pp.89-101.

5. Bashria, A., Yousef, A., Adam, N.M., Sopian, K., Zaharim, A. and Alghoul, M., 2007. Analysis of single and double passes Vgrooves solar collector with and without porous media. Int. J. Energy Environ, 2(1), pp.109-114. 
6. Kumar, C. and Singh, H., 2014. Experimental performance analysis of solar air heater with three different modifications in absorber plate. Int. J. Adv. Technol. Eng, 2(6), pp.79-86.

7. Dhatkar, S.A., Khandelwal, A.C. and Kanase-Patil, A.B., 2015. A Review of Solar Air Heaters using wire Mesh Absorber. International Journal on Theoretical and Applied Research in Mechanical Engineering (IJTARME), ISSN, pp.23193182.

8. Gupta, B., Waiker, J.K., Manikpuri, G.P. and Bhalavi, B.S., 2013. Experimental analysis of single and double pass smooth plate solar air collector with and without porous media. American Journal of Engineering Research, 2(12), pp.144-149.

9. Mahmood, A.J., 2015. Experimental Study of a Solar Air Heater with New Arrangement of Transverse Longitudinal Baffles and Wire Mesh Layers.

10. Fudholi, A., Sopian, K., Ruslan, M.H., Othman, M.Y. and Yahya, M., 2011. Thermal efficiency of double pass solar collector with longitudinal fins absorbers. American Journal of Applied Sciences, 8(3), p.254.

11. Kumar, Raj, et al. "CFD based analysis heat transfer and friction characteristics of broken multiple rib roughened solar air heater duct." Int J Mech Prod Eng Res Dev 3 (2013): 165-172.

12. Duffie, J.A. and Beckman, W.A., 1991. Solar engineering of thermal processes., New York. Chichester, Brisbane, Toronto, Singapore.

13. Manjunath, M. S., and N. Madhwesh. "A review of CFD investigations on heat transfer augmentation of forced convection solar air heater through enhanced fluid turbulence levels." International Journal of Mechanical and Production Engineering Research and Development 9.3 (2019): 1309-1322.

14. SRIVASTAVA, RAVISH KUMAR, and AJEET KUMAR RAI. "A REVIEW ON PERFORMANCE ENHANCEMENT OF SOLAR AIR HEATER." International Journal of Mechanical and Production Engineering Research and Development (IJMPERD) 7 , 5, Oct 2017, 279-288

15. PRASAD, BIKAS. "THERMAL ANALYSIS OF A SOLAR AIR HEATER INTEGRATED WITH FINNED ABSORBER PLATE." International Journal of Mechanical and Production Engineering Research and Development (IJMPERD) 8, 4, Aug 2018, 635-646

16. KIDIYOOR, ABHILASH, and KRIPA M. SUVARNA. "A STUDY ON PERFORMANCE OF SOLAR WATER HEATER USING LAURIC ACID-WATER AS THERMAL STORAGE SYSTEM." TJPRC: International Journal of Heat and Mass Transfer (TJPRC: IJHMT) 1, 1, Jun 2016, 9-14

17. Kumar, Sandeep, and Satbir Singh Sehgal. "Efficient Solar Collector Material and Working." International Journal 7.4 (2017): 29-38. 


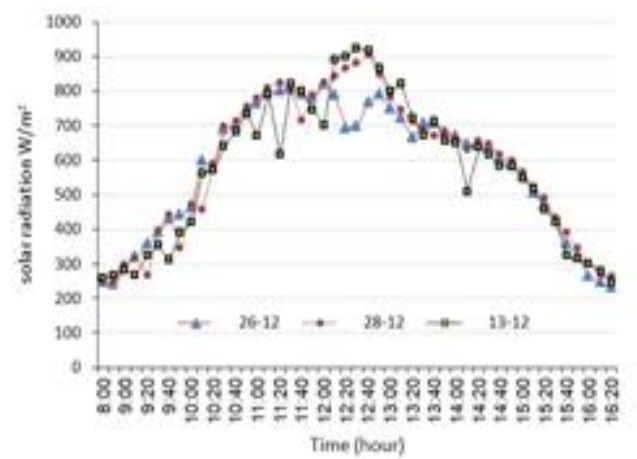

Figure 5: Variations of Solar Radiation for Days 13,26 and 28 of December 2019.

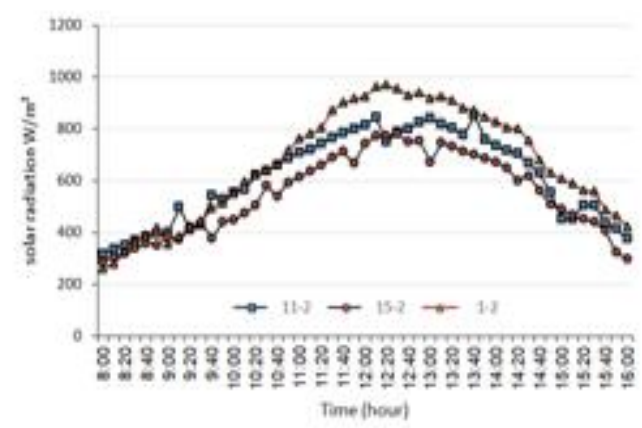

Figure 7: Variations of Solar Radiation for Days 1, 11 and 15 of Febuary 2020.

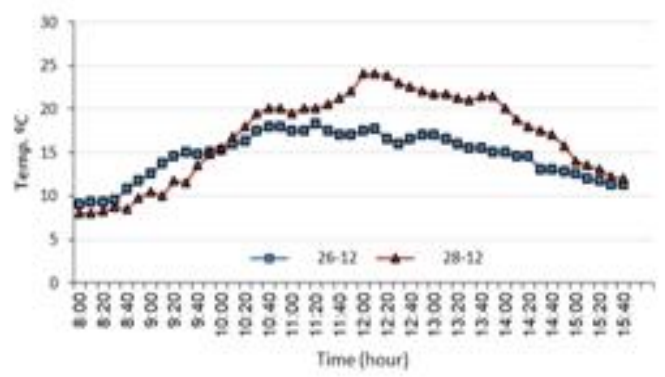

Figure 9: Variations of Ambient Temperature for Days 26 and 28 of December 2019.

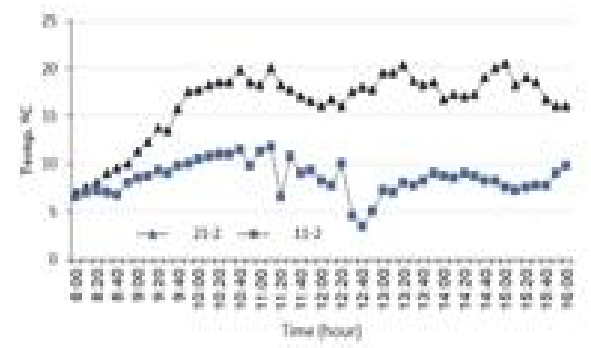

Figure 11: Variations of Ambient Temperature for days 11 and 21 of Febuary 2020.

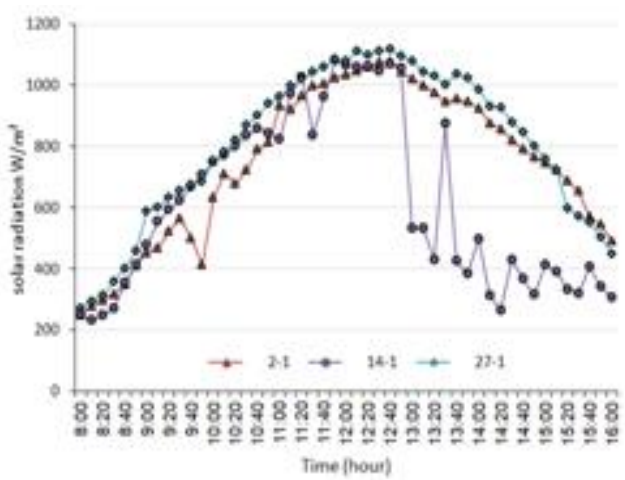

Figure 6: Variations of Solar Radiation for Days 2, 14 and 27 of January 2020.

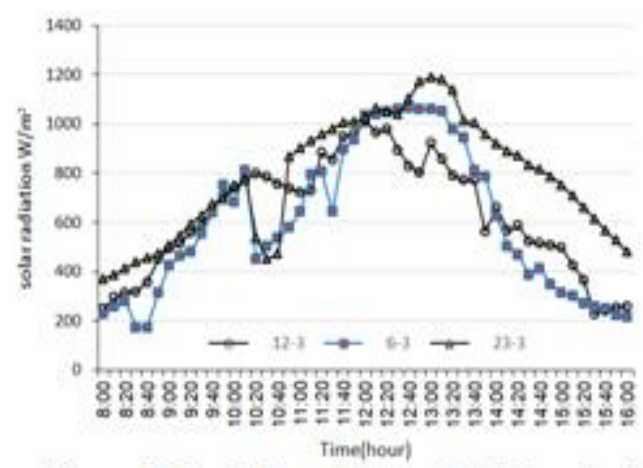

Figure 8: Variations of Solar Radiation for Days 6, 12 and 23 of March 2020.

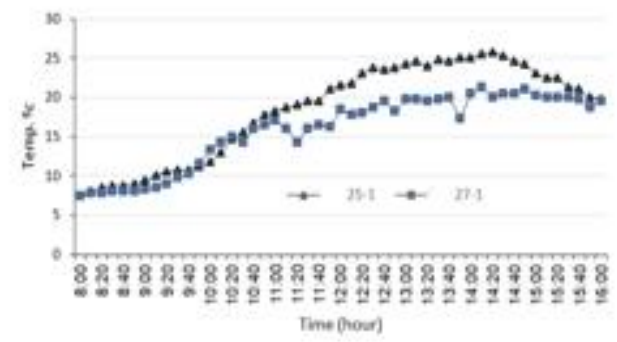

Figure 10: Variations of Ambient Temperature for days 25 and 27 of January 2020.

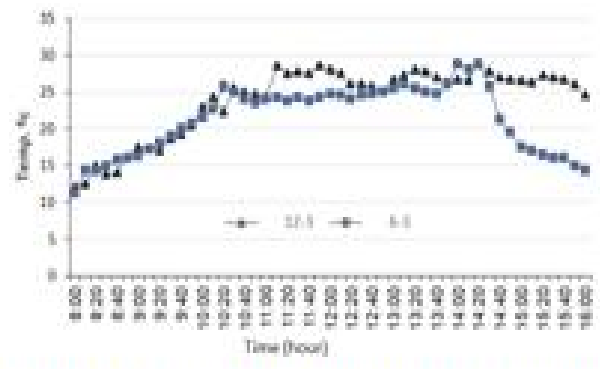

Figure 12: Variations of Ambient Temperature for days 6 and 12 of March 2020. 


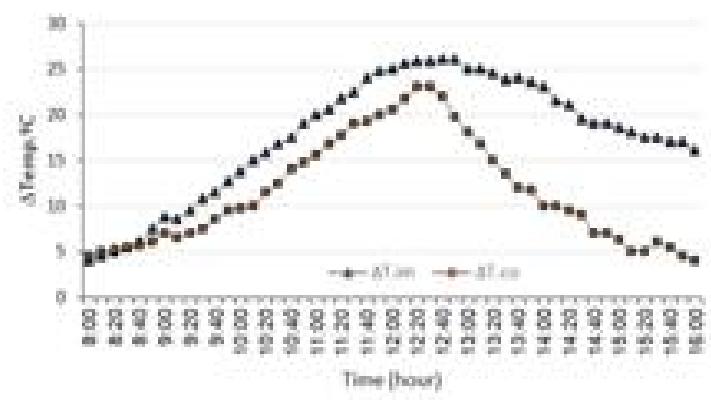

Figure 13: Variation of Temperature Difference for the Tro Heatern, on 26-12-2019.

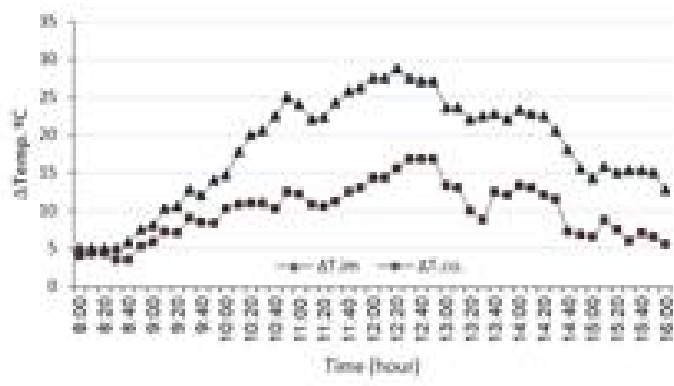

Figure (15): Variations of Temperature Difference for the Two Hesters, on 21-02-2020.

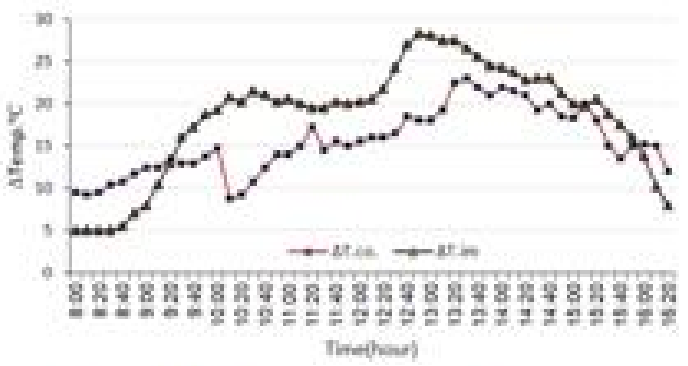

Figure (14):Variatiom of temperature difference for the two bestern, on 27-01-2020.

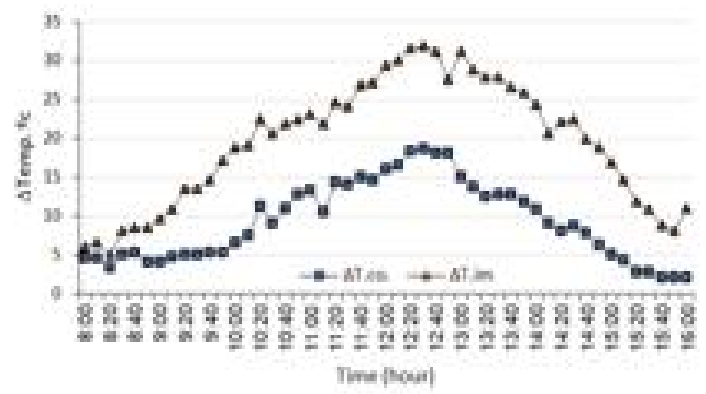

Figure (16):Variatiom of temperature difference for the two beaterz, on 12-03-2020.

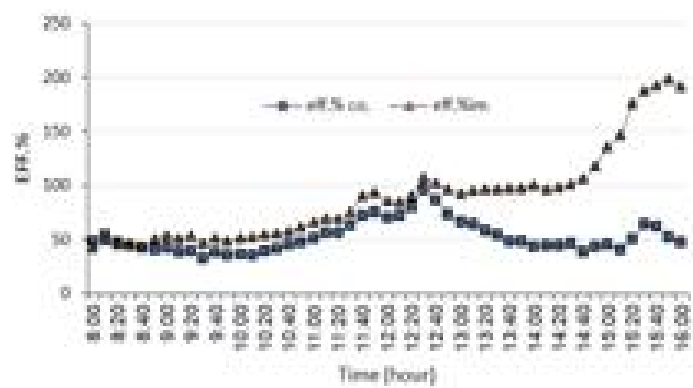

Figure (17):Veriations of thermal efficiency for the tre bestern, on 26-12-2019.

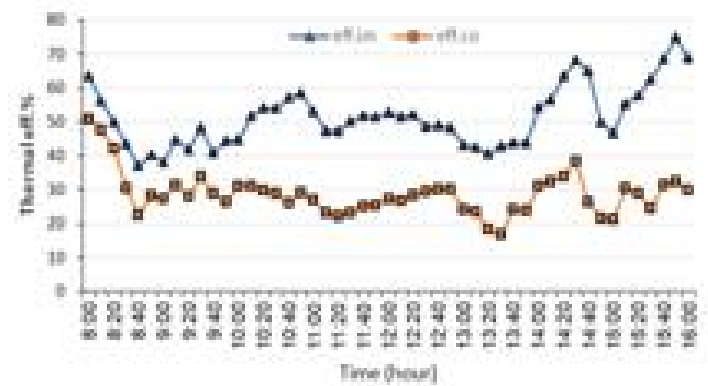

Figure (19):Variation of thermal efficiency for the tro beatera, on 21-02-2020.

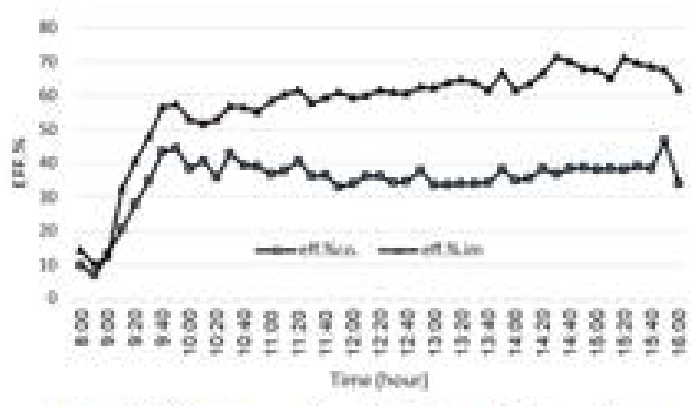

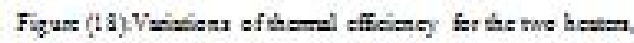
ox 27-01-2020.

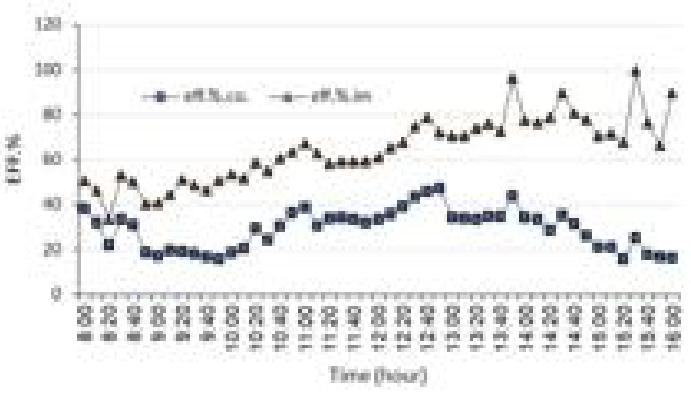

Figure (20):Yariatian of thermal effeces far the two beatern,an 12-49-2020 


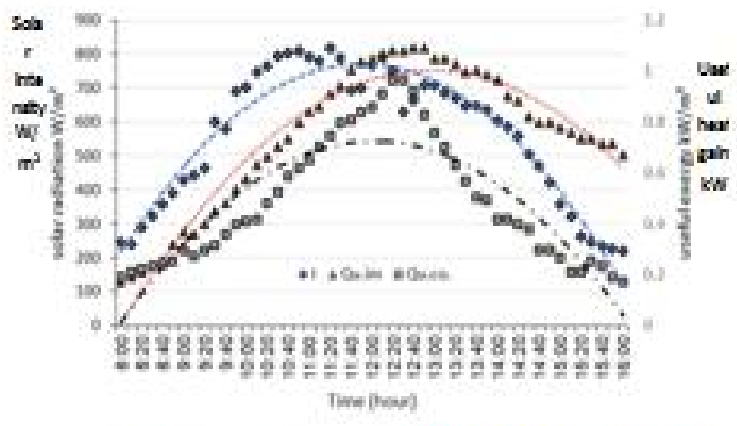

Figure (21):Variations ofweful beat gain for the two bexters, on 26-12-2019.

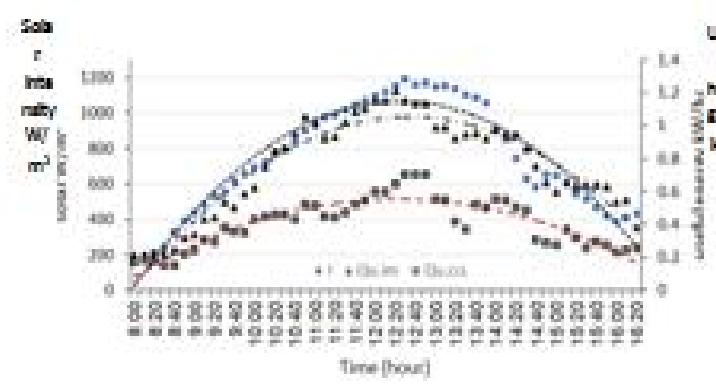

Figure (23):Variatione of weful beat gain for the tro besters, on 21-02-2020.

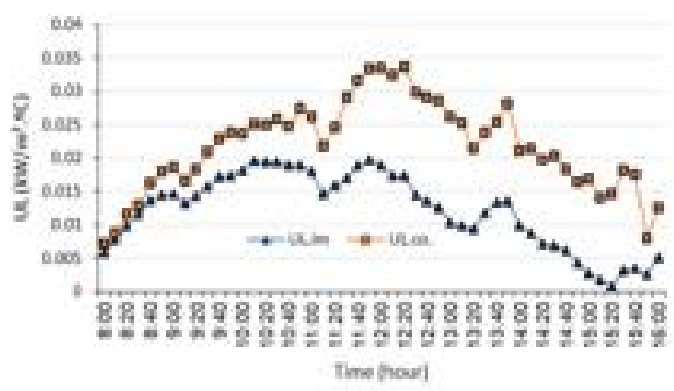

Figure (29):Veriatione of overall beat tramfer coefficient for the tro beatern, on 25-12-2019.

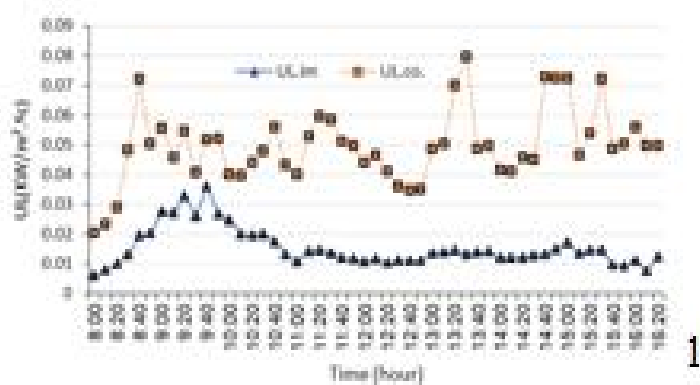

Figure (27):Variatiom of overall beat tremefer coefficient for the two beaters, on 21-02-2020.

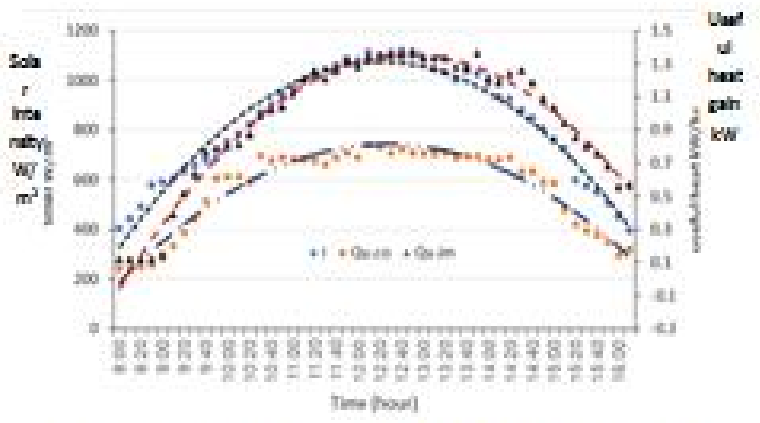

Figure (22):Variatiom ofuseful best gain for the two besters, on 27-01-2020.

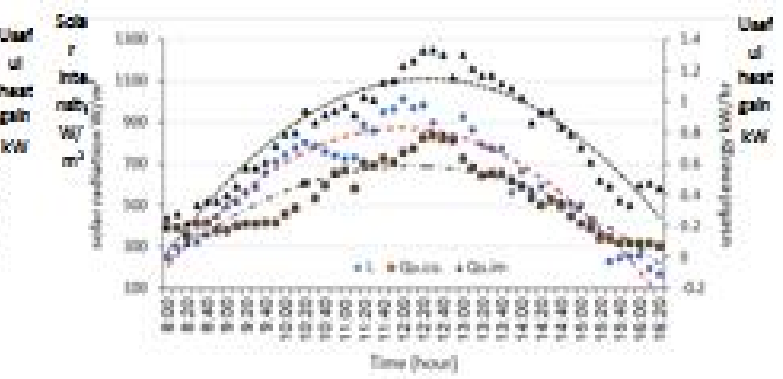

Figure (24):Variation of weful beat gxin for the tro besters, onl2-03-2020.

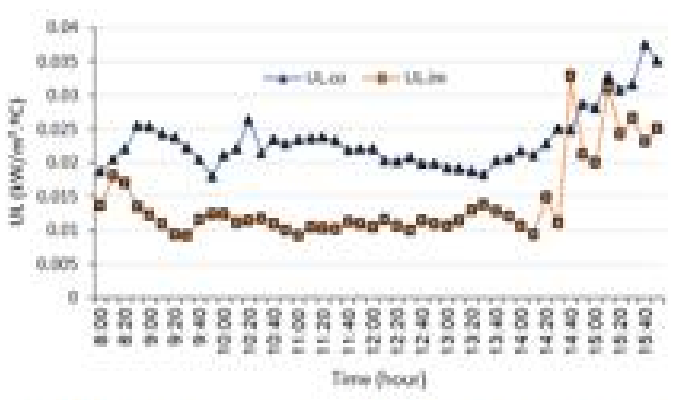

Figure (26):Variation of overall beat tranefer coefficient for the tro besters, on27-01-2020.

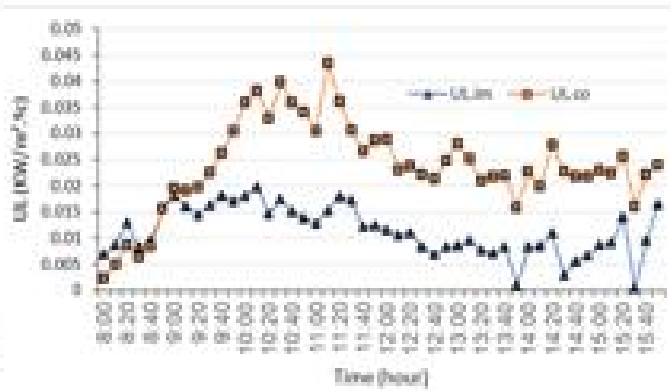

Figure (25): Variation of overall best tranfer coefficient for the tro beaters, 12-03-20020. 